\title{
Efficacy and safety of inhaled tacrolimus in rat lung transplantation
}

\author{
Noboru Ide, MD, ${ }^{a}$ Takeshi Nagayasu, MD, ${ }^{a}$ Keitarou Matsumoto, MD, ${ }^{a}$ Tsutomu Tagawa, MD, ${ }^{a}$ Kenji Tanaka, MD, ${ }^{a}$ \\ Tsunenori Taguchi, MD, ${ }^{a}$ Yorihisa Sumida, MD, and Mikiro Nakashima, $\mathrm{PhD}^{\mathrm{b}}$
}

From the Division of Surgical Oncology, Department of Translational Medical Sciences, Nagasaki University Graduate School of Biomedical Sciences, ${ }^{a}$ and the Division of Hospital Pharmacy, Nagasaki University Hospital of Medicine and Dentistry, ${ }^{\text {b }}$ Nagasaki, Japan.

Received for publication March 22, 2006; revisions received July 17, 2006; accepted for publication Sept 5, 2006.

Address for reprints: Takeshi Nagayasu, MD, Division of Surgical Oncology, Department of Translational Medical Sciences, Nagasaki University Graduate School of Biomedical Sciences, 1-7-1 Sakamoto, Nagasaki 852-8501, Japan (E-mail: nagayasu@ net. nagasaki-u.ac.jp).

J Thorac Cardiovasc Surg 2007;133:548-53 $0022-5223 / \$ 32.00$

Copyright (๑) 2007 by The American Association for Thoracic Surgery

doi:10.1016/j.jtcvs.2006.09.002
Objective: Because acute rejection is the most important cause of chronic rejection in lung transplantation, the use of conventional systemic immunosuppression to improve long-term survival needs to be reassessed. The aim of this study was to investigate the efficacy and safety of inhaled tacrolimus for preventing acute rejection of rat lung allografts.

Methods: Orthotopic left lung transplantation was performed in rats that were divided into 6 groups: control group received no treatment; groups 1.0-IM, 0.5-IM, and $0.3-\mathrm{IM}$ received tacrolimus by intramuscular injection at 1.0, 0.5, and 0.3 $\mathrm{mg} /(\mathrm{kg} \cdot \mathrm{d})$, respectively; and groups 12-IT and 6-IT received 12 and 6 puffs of inhaled tacrolimus 3 times per day, respectively. Allografts were studied histologically. Whole blood and allograft tacrolimus concentrations were determined.

Results: In groups 1.0-IM and 12-IT, histologic grade of the graft showed significantly less rejection than in the other groups. The blood tacrolimus concentration in group 12-IT $(4.87 \mathrm{ng} / \mathrm{mL})$ was significantly lower than that in group 1.0-IM (13.05 $\mathrm{ng} / \mathrm{mL}, P=.0017)$ on postoperative day 7 . Higher allograft tacrolimus concentrations were achieved in group 1.0-IM $(478.0 \mathrm{ng} / \mathrm{g})$ than in group 12-IT $(270.4 \mathrm{ng} / \mathrm{g}$, $P=.009)$. Weight loss and diarrhea in group 12-IT were less severe than in the groups that received systemic tacrolimus. The proliferating cell nuclear antigen index in bronchus-associated lymphoid tissue cells was significantly lower in group 12-IT than in group 1.0-IM $(P=.0209)$.

Conclusion: Local immunotherapy with inhaled tacrolimus has great potential for controlling pulmonary allograft rejection in clinical lung transplantation because it has fewer side effects than systemic immunosuppressive agents.

$\mathrm{D}$ espite the fact that lung transplantation is an accepted and established therapeutic option for a variety of end-stage lung diseases, ${ }^{1,2}$ chronic rejection, as manifested by obliterative bronchiolitis, is a limiting factor for achieving adequate long-term survival. Because acute rejection is the most important cause of chronic rejection, initial immunosuppression regimens that are based on cyclosporine (INN ciclosporin) or tacrolimus may have a significant impact on long-term allograft function. Several reports have found that patients who receive tacrolimus-based therapy appear to have immunosuppressive advantages similar to or slightly better than those of patients treated with cyclosporine. ${ }^{3-8}$ Tacrolimus has also been proven to be beneficial in the management of bronchiolitis obliterans syndrome as rescue therapy. ${ }^{9-11}$ Because the incidences among transplant recipients of infections, nephrotoxicity, diabetes, hypertension, and solid organ tumors are significant, the adverse effects of systemic immunosuppression are a serious problem. ${ }^{5,6,8}$

Ideal immunosuppression depends on two basic concepts. The first is the need to control early intragraft immune events directly; the second is the need to achieve 


\section{Abbreviations and Acronyms \\ BALT $=$ bronchus-associated lymphoid tissue \\ PCNA $=$ proliferating cell nuclear antigen \\ POD = postoperative day}

high local drug delivery while diminishing the adverse consequences of systemic immunosuppression. Lung tissue offers a unique opportunity to study the efficacy of local immunosuppression because of the ease with which airborne drugs may be deposited in the allograft by inhalation. ${ }^{12}$ Aerosolized cyclosporine has been used at the University of Pittsburgh Medical Center since 1993 as a rescue therapy for patients with lung acute rejection and appears to be effective in refractory chronic rejection. ${ }^{13-15}$ There have been few reports, however, regarding the usefulness of inhaled tacrolimus in lung transplantation. ${ }^{16}$ A prospective, randomized trial demonstrated that inhaled tacrolimus had a greater immunosuppressive potential than cyclosporine with respect to both acute and chronic rejection. ${ }^{17} \mathrm{We}$ therefore hypothesized that inhaled tacrolimus represents an alternative drug delivery system that might be ideal for successful lung transplantation. The aim of this study was to determine whether inhaled tacrolimus would prevent acute rejection of rat lung allografts and would provide effective graft concentrations with low systemic delivery in recipient rats relative to the intramuscular administration of tacrolimus.

\section{Materials and Methods \\ Animals}

Adult male inbred rats, 8 to 12 weeks old, were used for all the experiments. Transplantations were done with Brown Norway rats weighing 200 to $250 \mathrm{~g}$ as donors (SLC, Japan) and Lewis rats weighing 250 to $300 \mathrm{~g}$ as recipients (Charles River Japan, Yokohama, Japan).

\section{Lung Transplantation}

Unilateral orthotopic left lung transplantation was performed with the cuff technique, as described previously. ${ }^{18}$ The cold lung ischemic time ranged from 25 to 40 minutes. No antibiotic prophylaxis was given after the operation. All animals received humane care in compliance with the Guide for the Care and Use of Laboratory Animals of Nagasaki University.

\section{Immunosuppressive Drug and Administration}

Tacrolimus $0.1 \%$ as an inhalant and in powder form was provided as a gift by Astellas Pharma Inc, Tokyo, Japan. The tacrolimus powder was dissolved in saline solution for intramuscular injection. For the administration of inhaled tacrolimus, we used a double chamber (BUXCO Electronics, Inc, Osaka, Japan) to ensure that the animals were exposed to the drug (Figure 1). The chamber had separate head and body compartments, separated by a neck seal. The animal was placed in the chamber for 2 minutes,

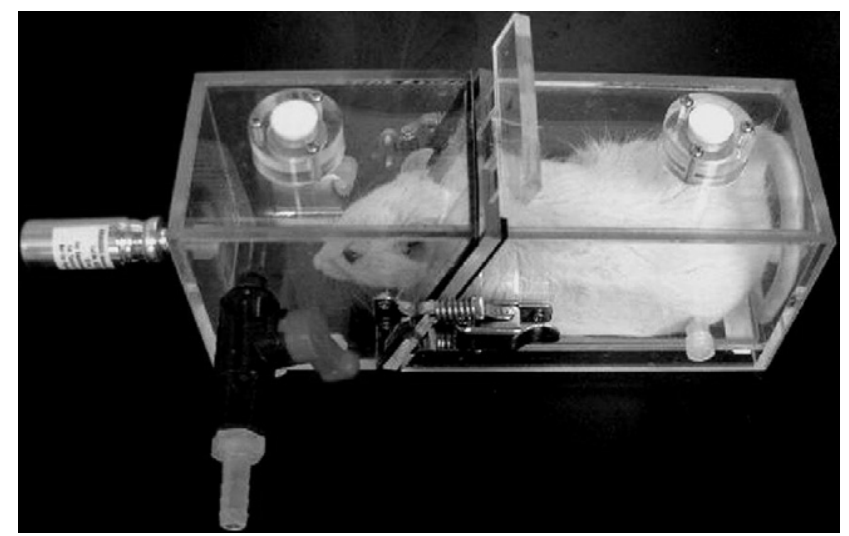

Figure 1. Double chamber was used to administer inhaled tacrolimus to ensure animals were exposed to appropriate dose.

and inhaled tacrolimus (50 $\mu \mathrm{g} / \mathrm{puff}$ ) was sprayed through the port located in the front wall of the head chamber.

\section{Experimental Groups and Immunosuppressive Therapy}

Recipients were divided into 6 experimental groups. The control group $(\mathrm{n}=7)$ received no immunosuppressant. Group 1.0-IM $(\mathrm{n}=7)$ received tacrolimus in powder form dissolved in saline solution by intramuscular injection at a dosage of $1 \mathrm{mg} /(\mathrm{kg} \cdot \mathrm{d})$; group 0.5-IM $(n=7)$ received tacrolimus in powder form dissolved in saline solution by intramuscular injection at a dosage of $0.5 \mathrm{mg} /(\mathrm{kg} \cdot \mathrm{d})$; and group 0.3-IM $(\mathrm{n}=7)$ received tacrolimus in powder form dissolved in saline solution by intramuscular injection at a dosage of $0.3 \mathrm{mg} /(\mathrm{kg} \cdot \mathrm{d})$. All animals received the first assigned tacrolimus dose within 1 hour of transplantation on postoperative day (POD) 0 . The same dose was dispensed every 24 hours until the animal was killed. The last intramuscular tacrolimus dose was given 24 hours before the animal was killed, and the specimens were harvested immediately thereafter. Group 12-IT $(n=7)$ received 12 puffs of $0.1 \%$ inhaled tacrolimus 3 times per day. Group 6-IT $(n=7)$ received 6 puffs of $0.1 \%$ inhaled tacrolimus 3 times per day. The last inhaled tacrolimus dose was administered 1 hour before the animal was killed. All recipients were killed on POD 7.

\section{Histologic Analysis}

All allografts and native lungs were divided after being harvested and were preserved in $4 \%$ paraformaldehyde in a phosphatebuffered saline solution. The specimens were embedded in paraffin, sectioned, stained with hematoxylin and eosin, and graded in a blinded fashion with the Yousem standardized nomenclature for lung allograft rejection. ${ }^{19}$ In brief, the grading scale was as follows: grade 0, no cellular infiltrates; grade 1, perivascular infiltrates of small round and transformed large lymphoid cells and immunoblasts and endothelitis; grade 2, perivascular mononuclear infiltrates with spread into adjacent alveolar septae and prominent alveolar macrophages; grade 3, perivascular mononuclear infiltrate with peribronchiolar inflammation, lymphocyte epidermotropism, 


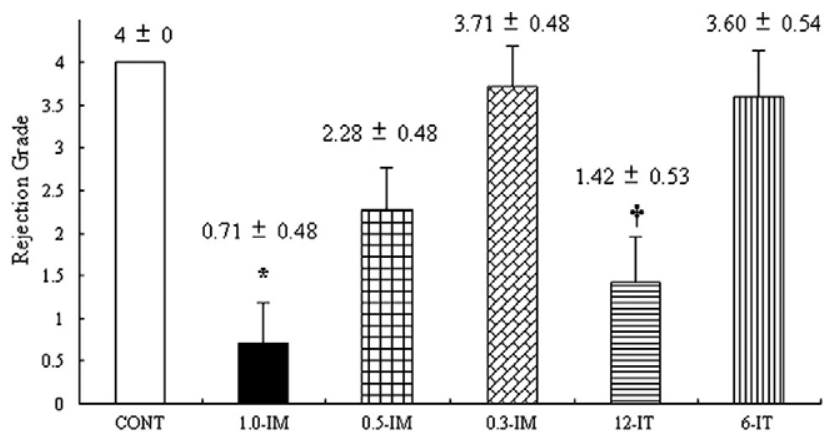

Figure 2. Rejection grade on POD 7. Differences among control, 0.3-IM, and 3-IT groups were not significant. In groups 1.0-IM and 12-IT, histologic grade of the graft showed significantly less rejection than in other groups $(P<.01)$.

* 1.0 IM vs. control $(p=0.0006), 0.5 \operatorname{IM}(p=0.0010), 0.3 \operatorname{IM}(p=0.0010), 12 \operatorname{IT}(p=0.0296), 6 \operatorname{IT}(p=0.0011)$

$\uparrow 12$ IT vs. control $(p=0.0007), 0.5 \operatorname{IM}(p=0.0146), 0.3 \operatorname{IM}(p=0.0011), 6 \operatorname{IT}(p=0.0012)$

epithelial cell and alveolar pneumocyte necrosis, diffuse interstitial pneumonitis, hyaline membranes, and intra-alveolar accumulation of neutrophils and macrophages; grade 4, vascular thrombosis with massive intra-alveolar hemorrhage and infarction and diffuse interstitial pneumonia with diffuse alveolar damage.

\section{Measurement of Tacrolimus}

Tacrolimus concentrations in whole blood and in homogenates of the allograft lungs were measured by the microparticle enzyme immunoassay method based on the Abbott IMX analyzer (Abbott Laboratories, Abbott Park, Ill).$^{20}$ Briefly, the microparticle enzyme immunoassay is a semiautomated immunoassay with a manual pretreatment step in which the sample is extracted with a precipitation reagent and centrifuged. The supernatant is entered into the immunoassay process, and the final fluorescent product is measured with the IMX analyzer. Tacrolimus concentrations in the homogenates of allograft lungs were measured with the same method.

\section{Proliferating Cell Nuclear Antigen Staining}

Proliferating cell nuclear antigen (PCNA) immunohistochemical staining was performed with a monoclonal murine antibody, PC10 (immunoglobulin G2a; DAKO A/S, Glostrup, Denmark) at a dilution of 1:100. The antibody, diluted with $0.05-\mathrm{mol} / \mathrm{L}$ tris(hydroxymethyl)aminomethane hydrochloride buffer, was applied to the deparaffinized tissue sections. The binding of PC10 was detected with the biotinylated secondary antibody and with peroxidase-labeled streptavidin (DAKO Corporation, Carpinteria, Calif). The sections were visualized with diaminobenzidine, and the nuclei were then stained with hematoxylin. Sections that were incubated with normal mouse immunoglobulin $\mathrm{G}$, instead of the primary antibody, served as negative controls. The bronchusassociated lymphoid tissue (BALT) cells in the allograft were examined and classified as positive for PCNA (red nuclei from fast red staining) or negative PCNA (blue nuclei from hematoxylin staining). The PCNA index (percentage of PCNA-positive nuclei) was determined from counts of more than 1000 cells. The BALT cell PCNA indices obtained for each group were compared.

\section{Statistical Analysis}

Comparisons of the grade of rejection among the experimental groups were made with the Mann-Whitney $U$ test. Unpaired
Student $t$-tests were used to compare blood or tissue tacrolimus concentrations among the experimental groups. Data are expressed as mean $\pm \mathrm{SD}$.

\section{Results}

With respect to the grading of rejection, all control group animals showed grade 4 severe destructive change of pulmonary rejection on POD 7. Animals in group 1.0-IM had a mean rejection grade of $0.71 \pm 0.48$, those in group 0.5 -IM had a mean grade of $2.28 \pm 0.48$, and those in group 0.3-IM had a mean grade of $3.71 \pm 0.48$. Animals in group 12-IT showed minimal changes with a mean rejection grade of $1.42 \pm 0.53$; those in group 6-IT showed intense perivascular infiltrates with a mean rejection grade of $3.60 \pm 0.54$. Figure 2 shows the rejection grade for each group. There were no significant differences among the control, 0.3-IM, and 6-IT groups. Animals in groups 1.0-IM and 12-IT showed significantly less rejection than in the other groups $(P<.01)$.

To confirm that there was no transient elevation of blood tacrolimus concentration levels in the inhaled tacrolimus group, the last time that the dose was given was taken into account separately for both the inhaled and systemic groups. Thus in group 12-IT the blood and allograft tacrolimus concentrations were measured 1 hour after each dose was given (3 times per day), and in group 1.0-IM they were measured 24 hours after the last dose. Whole blood tacrolimus concentrations on POD 7 (Figure 3) were 13.05 \pm 4.65 $\mathrm{ng} / \mathrm{mL}$ in group $1.0-\mathrm{IM}, 7.88 \pm 0.84 \mathrm{ng} / \mathrm{mL}$ in group 0.5 -IM, $4.45 \pm 1.88 \mathrm{ng} / \mathrm{mL}$ in group $0.3-\mathrm{IM}, 4.87 \pm 1.39$ $\mathrm{ng} / \mathrm{mL}$ in group $12-\mathrm{IT}$, and $2.40 \pm 0.63 \mathrm{ng} / \mathrm{mL}$ in group 6-IT. Blood tacrolimus concentration was significantly lower in group 12-IT than in groups 1.0-IM $(P=.0017)$ and 0.5 -IM $(P=.0033)$. The allograft tacrolimus concentrations on POD 7 (Figure 4) were $478.0 \pm 43.2 \mathrm{ng} / \mathrm{g}$ in group 1.0-IM, $233.7 \pm 40.5 \mathrm{ng} / \mathrm{g}$ in group $0.5-\mathrm{IM}, 147.5 \pm 13.7$ $\mathrm{ng} / \mathrm{g}$ in group $0.3-\mathrm{IM}$, and $270.4 \pm 21.1 \mathrm{ng} / \mathrm{g}$ in group 12-IT. Higher allograft tacrolimus concentrations were 


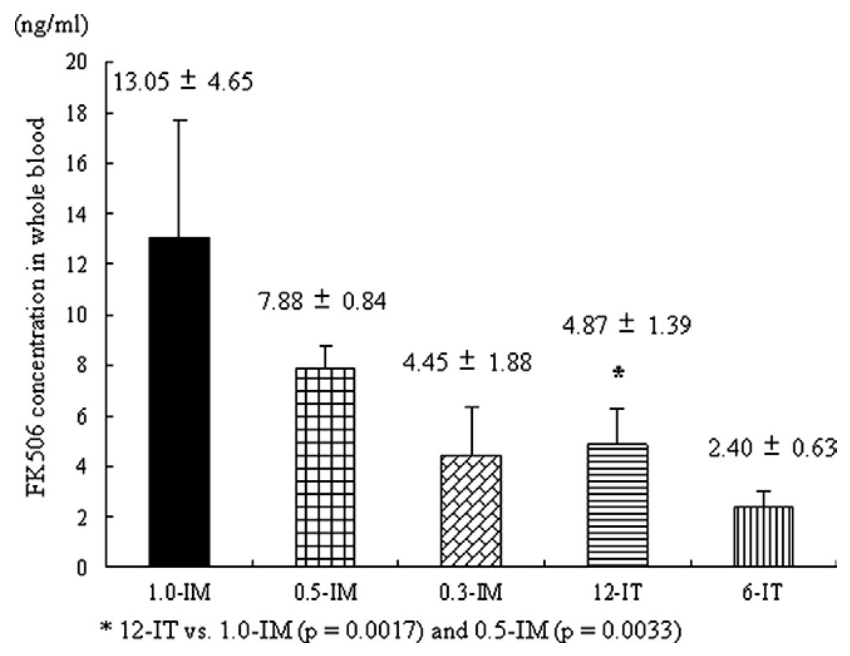

Figure 3. Tacrolimus (FK506) concentrations in whole blood were measured with microparticle enzyme immunoassay method.

achieved in group 1.0-IM than in group 0.5-IM $(P=.009)$ and group 12-IT $(P=.009)$.

Weight loss and diarrhea were common side effects. Weight losses were $26.6 \pm 5.7 \mathrm{~g}$ in the control group, $50 \pm$ $10.0 \mathrm{~g}$ in group 1.0-IM, $40 \pm 8.1 \mathrm{~g}$ in group 0.5 -IM, $22.5 \pm$ $14.6 \mathrm{~g}$ in group 0.3-IM, $20.0 \pm 8.6 \mathrm{~g}$ in group 12-IT, and $26.0 \pm 5.4 \mathrm{~g}$ in group 6-IT. Weight loss in group 12-IT was less severe than in groups 1.0-IM $(P=.0014)$ and 0.5 -IM $(P=.0015)$. All group 1.0-IM rats had diarrhea. Five of seven animals $(71.4 \%)$ in group 0.5 -IM and 1 of $7(14.3 \%)$ in groups 0.3-IM and group 12-IT had diarrhea. No animals in the control and 6-IT groups had diarrhea. Diarrhea in group 12-IT was less severe than in groups 1.0-IM $(P=$ $.0018)$ and 0.5 -IM $(P=.0374)$.

On POD 7, the BALT cell PCNA indices in the allografts were $21.3 \% \pm 7.8 \%$ in group 1.0-IM (Figure 5, $A$ ), $26.2 \% \pm 6.3 \%$ in group $0.5-\mathrm{IM}$, and $6.3 \% \pm 2.2 \%$ in group 12-IT (Figure 5, $B$ ). The BALT cell PCNA index was significantly lower in group 12-IT than in groups 1.0-IM $(P=.0209)$ and 0.5-IM $(P=.0209$, Figure 6).

\section{Discussion}

The current success of lung transplantation is largely attributable to the effectiveness of immunosuppressive therapy. The inconsistent control of acute rejection by systemic immunosuppression, however, which is almost universally predictable after lung transplantation, is still a major cause of low 5-year survival. ${ }^{21}$ Despite enhanced immunosuppression, a subset of patients have refractory acute rejection, and nearly $50 \%$ of lung transplant recipients have obliterative bronchiolitis develop. ${ }^{22}$ In addition, long-term use of systemic immunosuppression has resulted in significant drugrelated morbidity. $5,6,8$

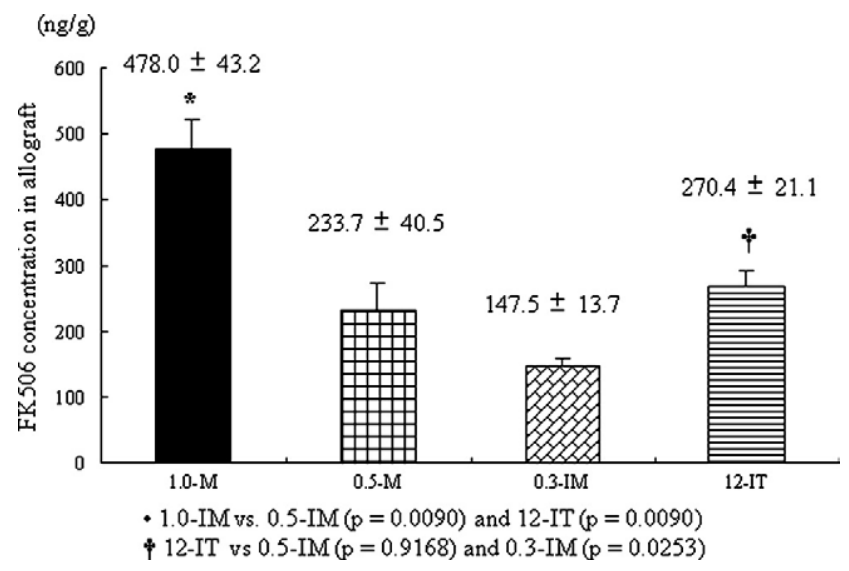

Figure 4. Tacrolimus (FK506) concentrations in homogenates of allograft lungs were measured with microparticle enzyme immunoassay method.

Since 1993, aerosolized cyclosporine has been used at the University of Pittsburgh Medical Center as a rescue therapy for patients with lung rejection, and it appears to be effective in reversing rejection. ${ }^{13-15}$ Recently, a randomized trial of inhaled cyclosporine in lung transplant recipients indicated that inhaled cyclosporine improved survival and extended the period of chronic rejection-free survival without improving the rate of acute rejection. ${ }^{23}$ Increasing evidence suggests that the acute rejection process is initiated and modulated locally within the allograft. Alloactivation by major histocompatibility complex antigens on passenger leukocytes in the graft provokes an intense inflammatory reaction, resulting in a rapid influx of neutrophils and macrophages. The subsequent release of cytokines and nitric oxide promotes local macrophage amplification and donorspecific T- and B-cell clonal expansion. Thus regional immunotherapy is a logical approach for achieving early high local drug levels that would inhibit the expression of allograft recognition targets, cytokine release, and effector cell function and migration to the allograft. ${ }^{24}$ Iacono and colleagues ${ }^{14}$ demonstrated that aerosolized cyclosporine reduced interleukin- 6 messenger RNA expression by lung graft bronchoalveolar lavage cells.

Prop and associates ${ }^{25}$ have suggested that the BALT magnifies the interaction between the pulmonary graft and the recipient host that likely accelerates the induction of the rejection response, both locally in the graft and systemically, in the recipient's lymphoid organs. Our group has previously found the expression of PCNA to be associated with acute cellular rejection of the bronchial epithelium and the BALT cells. In this study, we found that aerosol tacrolimus effectively suppresses the expression of PCNA in BALT cells. Furthermore, at the alveolar level, there were fewer PCNA-positive infiltrating cells in the inhaled tacroli- 

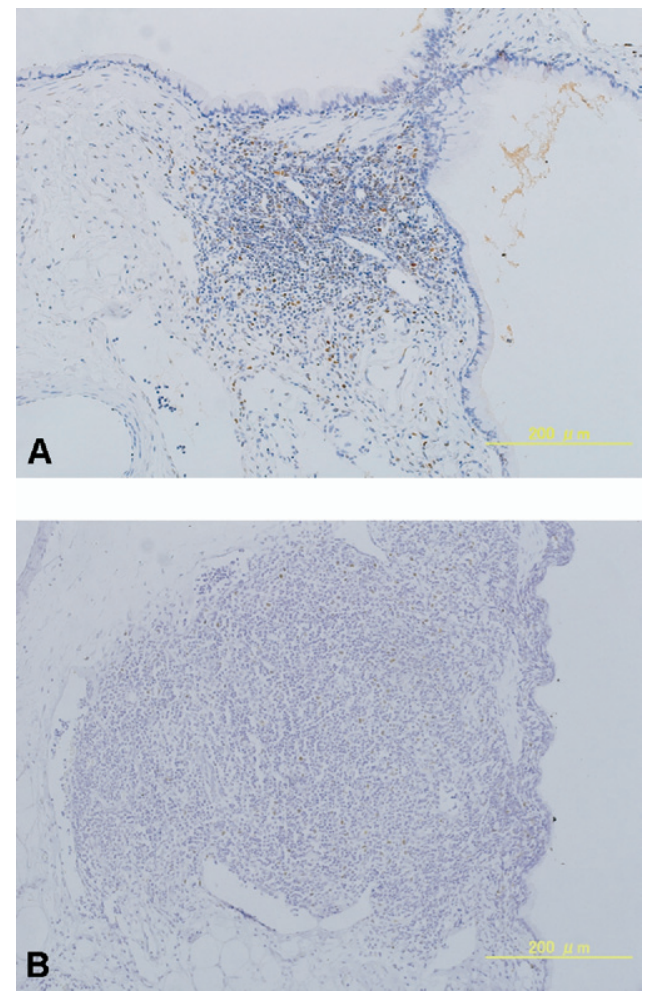

Figure 5. Proliferating cell nuclear antigen staining with labeled streptavidin biotin-alkaline phosphatase enzyme system in bronchus-associated lymphoid tissue cells present in allografts on postoperative day 7. A, Proliferating cell nuclear antigen-positive cells are present in bronchus-associated Iymphoid tissue of animal from group 1.0-IM. B, Proliferating cell nuclear antigen-positive cells are rarely observed in bronchus-associated lymphoid tissue of animal from group 12-IT. Brown dots indicate proliferating cell nuclear antigen.

mus group than in the systemic tacrolimus group (data not shown). Thus it would appear that inhaled tacrolimus might have different mechanisms from systemic tacrolimus for the local control of the interaction between pulmonary graft cells and the infiltrating recipient cells.

To control acute pulmonary rejection, a timed dosage of 12 puffs of tacrolimus was required 3 times per day, which resulted in a daily tacrolimus dose of $1.8 \mathrm{mg}$. Ingu and colleagues ${ }^{16}$ demonstrated that 10 puffs of inhaled tacrolimus and the intramuscular administration of $1.0 \mathrm{mg} /(\mathrm{kg} \cdot \mathrm{d})$ of tacrolimus had similar degrees of effectiveness in the same animal models. In our preliminary study, however, a single daily dosage of 12 puffs of tacrolimus was not found to be effective. Although a double-chamber system was useful for exposing the animals to the drug, the dead space of the chamber makes it difficult to determine the precise inhalation volume from the animals' airways. Furthermore, the effect of reperfusion injury, the status of bronchial anasto-

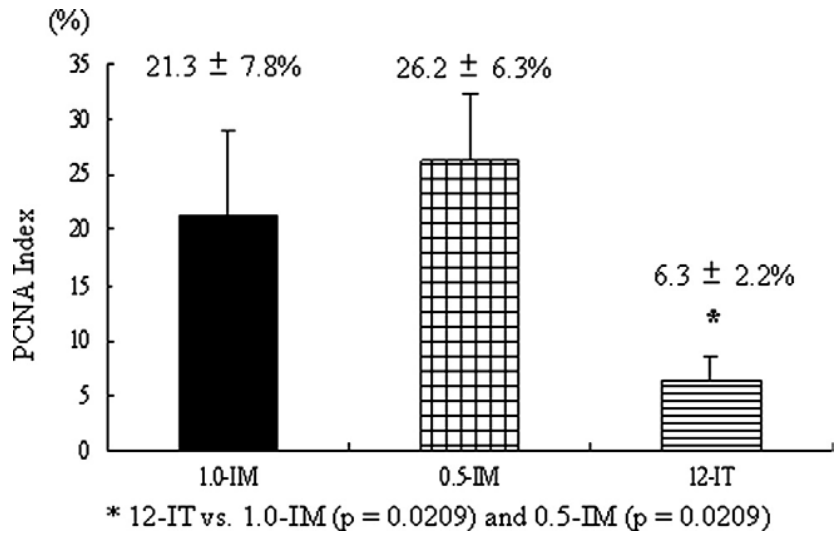

Figure 6. Bronchus-associated lymphoid tissue cell proliferating cell nuclear antigen index of allografts on postoperative day 7. Bronchus-associated lymphoid tissue cell proliferating cell nuclear antigen index was significantly lower in group 12-IT than in groups 1.0-IM $(P=.0209)$ and 0.5-IM $(P=.0209)$.

mosis, and the impairment of mucociliary function might affect the inhalation efficiency of the lung allograft.

Infections and side effects remain important issues with systemic immunosuppression. Although the incidences of infections in tacrolimus- and cyclosporine-treated recipients were found to be similar, there was a trend toward more fungal infections in the tacrolimus group. ${ }^{7}$ Furthermore, although the incidence of drug-related side effects were similar in the two groups, new-onset diabetes mellitus requiring antidiabetic medication was a side effect that was characteristically found in the tacrolimus group. ${ }^{8}$ Our study highlights the safety of inhaled tacrolimus, which is associated with less systemic toxicity than is intramuscular tacrolimus. The weight loss and diarrhea seen in group 12-IT were significantly less severe than in group 1.0-IM. In group 12-IT, the blood and allograft tacrolimus concentrations were measured 1 hour after each dose was given ( 3 times per day) and were found to be lower than the blood and allograft tacrolimus concentrations in group 1.0-IM 24 hours after the last dose. This indicates that the high dose of inhaled tacrolimus absorbed from the airway surface did not directly increase blood tacrolimus levels, whereas the high dose of systemic tacrolimus continued to increase blood and allograft tacrolimus levels. These results strongly suggest that inhaled tacrolimus is superior to systemic tacrolimus with respect to decreasing the incidence of side effects.

In conclusion, we found that inhaled tacrolimus used as local immunotherapy prevented acute rejection and offered effective allograft tacrolimus concentrations with low systemic drug delivery. Thus inhaled tacrolimus has great clinical potential to control and treat pulmonary rejection in lung allograft recipients. As has been seen with aerosolized 
cyclosporine, inhaled tacrolimus may also have promise in treating and preventing obliterative bronchiolitis. ${ }^{26}$

We gratefully acknowledge the expert technical assistance of Hiroaki Nakao.

\section{References}

1. Davis RD, Pasque MK. Pulmonary transplantation. Ann Surg. 1995; 221:14-28.

2. Trulock EP. Lung transplantation. Am J Respir Crit Care Med. 1997; 155:789-818.

3. Griffith BP, Bando K, Hardesty RL, Armitage JM, Keenan RJ, Pham $\mathrm{SM}$, et al. A prospective randomized trial of FK506 versus cyclosporine after human pulmonary transplantation. Transplantation. 1994;57: 848-51.

4. Keenan RJ, Iacono A, Dauber JH, Zeevi A, Yousem SA, Ohori NP, et al. Treatment of refractory acute allograft rejection with aerosolized cyclosporine in lung transplant recipients. Ann Thorac Surg. 1997;133: 335-41.

5. Kur F, Reichenspurner H, Meiser BM, Welz A, Furst H, Muller C, et al. Tacrolimus (FK506) as primary immunosuppressant after lung transplantation. Thorac Cardiovasc Surg. 1999;47:174-8.

6. Reichenspurner H, Kur F, Treede H, Meiser BM, Deutsch O, Welz A, et al. Optimization of the immunosuppressive protocol after lung transplantation. Transplantation. 1999;68:67-71.

7. Treede H, Klepetko W, Reichenspurner H, Zuckermann A, Meiser B, Birsan T, et al. Tacrolimus versus cyclosporine after lung transplantation: a prospective, open, randomized two-center trial comparing two different immunosuppressive protocols. J Heart Lung Transplant. 2001;20:511-7.

8. Zuckermann A, Reichenspurner H, Birsan T, Treede H, Deviatko E, Reichart B, et al. Cyclosporine A versus tacrolimus in combination with mycophenolate mofetil and steroids as primary immunosuppression after lung transplantation: one-year results of a 2-center prospective randomized trial. J Thorac Cardiovasc Surg. 2003;125:891-900.

9. Kesten S, Chaparro C, Scavuzzo M, Gutierrez C. Tacrolimus as rescue therapy for bronchiolitis obliterans syndrome. J Heart Lung Transplant. 1997;16:905-12.

10. Ross DJ, Lewis MI, Kramer M, Vo A, Kass RM. FK506 'rescue' immunosuppression for obliterative bronchiolitis after lung transplantation. Chest. 1997;112:1175-9.

11. Verleden GM, Dupont LJ, Van Raemdonck D, Vanhaecke J. Effect of switching from cyclosporine to tacrolimus on exhaled nitric oxide and pulmonary function in patients with chronic rejection after lung transplantation. J Heart Lung Transplant. 2003;22:908-13.

12. Mitruka SN, Pham SM, Zeevi A, Li S, Cai J, Burckart GJ, et al. Aerosol cyclosporine prevents acute allograft rejection in experimental lung transplantation. J Thorac Cardiovasc Surg. 1998;115:28-37.
13. Iacono AT, Keenan RJ, Duncan SR, Smaldone GC, Dauber JH, Paradis IL, et al. Aerosolized cyclosporine in lung recipients with refractory chronic rejection. Am J Respir Crit Care Med. 1996;153: 1451-5.

14. Iacono AT, Smaldone GC, Keenan RJ, Diot P, Dauber JH, Zeevi A, et al. Dose-related reversal of acute lung rejection by aerosolized cyclosporine. Am J Respir Crit Care Med. 1997;155:1690-8.

15. Keenan RJ, Iacono A, Dauber JH, Zeevi A, Yousem SA, Ohori NP, et al. Treatment of refractory acute allograft rejection with aerosolized cyclosporine in lung transplant recipients. J Thorac Cardiovasc Surg. 1997;113:335-40.

16. Ingu A, Komatsu K, Ichimiya S, Sato N, Hirayama Y, Morikawa M, et al. Effects of inhaled FK 506 on the suppression of acute rejection after lung transplantation: use of a rat orthotopic lung transplantation model. J Heart Lung Transplant. 2005;24:538-43.

17. Keenan RJ, Konishi H, Kawai A, Paradis IL, Nunley DR, Iacono AT, et al. Clinical trial of tacrolimus versus cyclosporine in lung transplantation. Ann Thorac Surg. 1995;60:580-5.

18. Mizuta T, Kawaguchi A, Nakahara K, Kawashima Y. Simplified rat lung transplantation using a cuff technique. J Thorac Cardiovasc Surg. 1989;97:578-81.

19. Yousem SA, Berry GJ, Cagle PT, Chamberlain D, Husain AN, Hruban $\mathrm{RH}$, et al. Revision of the 1990 working formulation for the classification of pulmonary allograft rejection: Lung Rejection Study Group. J Heart Lung Transplant. 1996;15:1-15.

20. Dietemann J, Berthoux P, Gay-Montchamp JP, Batie M, Berthoux F. Comparison of ELISA method versus MEIA method for daily practice in the therapeutic monitoring of tacrolimus. Nephrol Dial Transplant. 2001;16:2246-9.

21. Bennett LE, Keck BM, Daily OP, Novick RJ, Hosenpud JD. Worldwide thoracic organ transplantation: a report from the UNOS/ISHLT International Registry for Thoracic Organ Transplantation. Clin Transpl. 2000:31-44.

22. Bando K, Paradis IL, Similo S, Konishi H, Komatsu K, Zullo TG, et al. Obliterative bronchiolitis after lung and heart-lung transplantation: an analysis of risk factors and management. J Thorac Cardiovasc Surg. 1995;110:4-14.

23. Iacono AT, Johnson BA, Grgurich WF, Youssef JG, Corcoran TE, Seiler DA, et al. A randomized trial of inhaled cyclosporine in lungtransplant recipients. $N$ Engl J Med. 2006;354:141-50.

24. Ruers TJ, Buurman WA, Van der Linden CJ, Kootstra G, Ruers TJ, Buurman WA, van der Linden CJ, Kootstra G. Transplant Proc. 1987;19:246-8.

25. Prop J, Wildevuur CR, Neiuwenhuis P. Lung allograft rejection in the rat. Transplantation. 1985;40:126-31.

26. Nagayasu T, Oka T, Sawada T, Tamura K, Shirafuji T, Ryu C, et al. Expression of proliferating cell nuclear antigen in bronchial epithelium after lung transplantation in the rat. J Heart Lung Transplant. 1998; 17:566-72. 